\title{
Systems Technicians: Electronics Foundation With Photonics, Robotics and Other Specialties
}

\author{
Mr. Daniel M. Hull P.E., OP-TEC
}

Registered Professional Engineer, BSEE Univ. Texas, MSEE Univ. Pitt, PI and Executive Director, OPTEC, NSF/ATE National Center for Optics and Photonics Education

\section{Dr. Chrysanthos Andreas Panayiotou, Indian River State College}

Dr. Chrysanthos A. Panayiotou is the director of the National Science Foundation Southeast Regional Center for Laser and Fiber Optics based at Indian River State College in Fort Pierce Florida. For the last 20 years he served as electronics professor, program director and department chair of the electronics and electrical power technology programs at Indian River State College and Brevard Community College where he created new courses and programs, updated curricula, and increased enrollment to full capacity. Chrysanthos authored two textbooks and six laboratory manuals in the areas of analog and digital electronics, and schematic capture and printed circuit board layout. Panayiotou started his career in industrial controls and automation and then transitioned to the telecommunications industry where he designed VHF and UHF networks. Panayiotou received his undergraduate electrical engineering degree from Higher Technical Institute, Nicosia, Cyprus. With the support from a Fulbright scholarship, he completed his master's degree in electrical engineering at the University of Central Florida. Chrysanthos continued his graduate studies at Florida Atlantic University, Boca Raton, Florida, where he received a doctoral degree in educational leadership. 


\title{
Systems Technicians: Electronics Foundation with Photonics, Robotics and Other Specialties
}

\begin{abstract}
Employment trends for technicians in the physical sciences are calling for broad-based technical knowledge and skills, with a specialization in an emerging technology, such as photonics, robotics \& automation, instrumentation \& control, biomedical equipment etc. The AAS degree curriculum for preparing these techs typically includes a technical core of electronics, plus 3-4 specialty courses in one of these emerging technologies. An example that has been tested and proven very successful is in Photonics.

Indian River State College (FL) converted its EET program to the Photonics Systems Technology (PST) curriculum structure in 2008, including several other specialties such as robotics, fiber optics communications, instrumentation \& control, and biomedical equipment. This change reenergized IRSC's rapidly declining Electronics program. Enrollment at IRSC is now at a maximum capacity and completers are highly sought by employers in industries such as photonics, communications, automated systems, defense and environmental control. Completers of the programs receive AAS degrees in Electronics with a specialty in Photonics, etc. Design of the curriculum is based on OP-TEC's National Photonics Skill Standards and focus groups of photonics technician employers.
\end{abstract}

\section{Background}

The field of electronics has experienced several significant revolutions that have led to new requirements for electronic technicians. From the discovery of the first active device, the triode vacuum tube, electronics focused primarily on radio and radars for the first half of the $20^{\text {th }}$ century. During this period, the few electronic technicians available were the products of private schools and the military. With the emergence of television and transistors, the need for electronics techs grew to support entertainment devices as well as further needs for military guidance and communications systems. AAS degree programs to educate electronic technicians were formed at two-year technical colleges during the 1960s. As more solid state devices and digital integrated circuits were developed, electronics grew in the 1970s, encompassing industrial applications, military and space systems, consumer electronics and control systems. To support these applications, most two-year colleges offered electronics technician education. In the 1980s and 1990s electronics technology was among the most popular technical program at community and technical colleges. Technical educators were required to make relatively frequent and substantive changes in the AAS degree Electronics curriculum in order to produce technicians with up-to-date skills.

Since 1975, specialized engineering technology programs, such as laser/electro-optics, biomedical electronics, telecommunications, industrial electronics and robotics have emerged. Although these fields are heavily dependent on electronics, most of the specialized AAS degree curricula concentrated on the specialty. For example, laser electro-optics programs contained eight to ten specialty courses-and consequently less electronics. 
Current and Future Trends: "Systems Technicians”

In the early 2000s electronics began transitioning to an "enabling technology" for many of these specialty areas. One example is in photonics. As lasers moved from the R\&D stage to applications where they were a subsystem in a variety of equipment, such as welders, surgical instruments, fiber-optics communications, printers etc., an in-depth knowledge and skills for laser technicians was not as critical as having fewer specialty courses, layered on a broad technical base that allows technicians to integrate, operate, maintain, trouble shoot and repair systems. Similar examples are also evident as IT and Communications merged and Robotics merged with Manufacturing. Today, demand for these "system-oriented technicians" is high.

The NSF/ATE National Center for Optics and Photonics Education (OP-TEC) ${ }^{1}$ recently conducted a survey of employers that revealed a need for $\sim 800$ new technicians per year for at least the next five years. ${ }^{2}$ Using focus groups of photonics employers OP-TEC determined that the high degree of specialization (8-10 specialty courses in an AAS degree) is only required for $\sim 15 \%$ of the new photonics technicians; $85 \%$ of the need is for "Photonics Systems

Technicians", working in applications, where photonics is an "enabling technology" in many fields. The definition of a PST was created from information in the employer focus groups.

Photonics systems technicians (PSTs) work in industries whose processes and operations require the extensive use of photonics devices to meet production or mission goals. PSTs frequently integrate photonics devices or subsystems into larger systems, where photonics is an enabling technology. PSTs must have broad, working knowledge and skills of electronic and electromechanical devices/systems, combined with their specialty knowledge and skills in photonics to efficiently and effectively operate, maintain, repair, and calibrate photonics subsystems, and integrate these subsystems into full systems.

New curricula designs for PSTs require only 3-4 photonics courses, supported by an electronics technical core. Colleges initiating or revising photonics programs can utilize much of their existing electronics curricula and reduce the technical specialization from 8-10 photonics courses to 3-4 courses. This new strategy not only addresses most of the job requirements, it requires only one photonics faculty member instead of 3 or 4 , and less than $\$ 225,000$ of lab equipment instead of \$2-3 million. In the present economic condition of state or locally supported community colleges, the cost for initiating and offering this type of a program is reasonable and achievable. $^{3}$

This model can be extended to other specialty areas, such Robotics, Biomedical Equipment, Instrumentation and Telecommunications. The model can be illustrated by the following chart. 
AAS Degree in Electronics with Systems Specialty Certificates

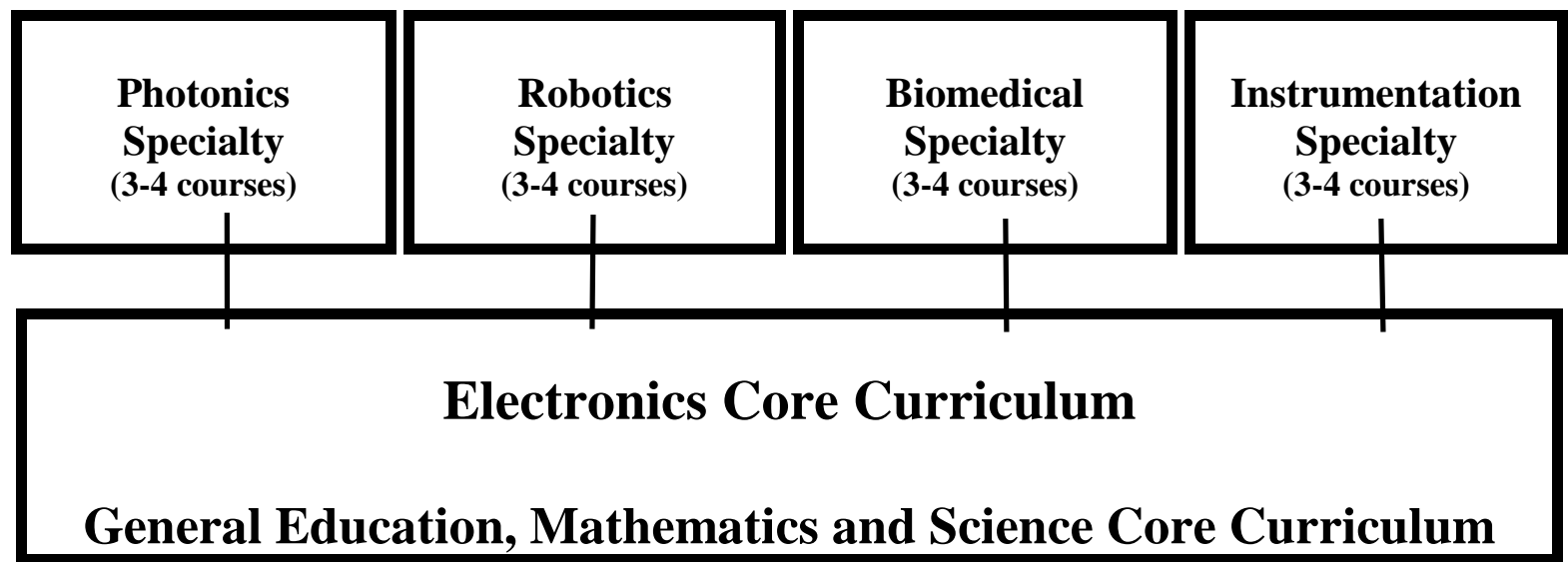

Figure 1. Systems Technician Curriculum Model

An Example of Implementing the Systems Technician Curriculum

Prior to 2005, Indian River Community College (now Indian River State College) offered a traditional Electronics Engineering Technology AAS degree program. From 1995 to 2005, enrollment in the EET program dropped from 158 students to 55 students. Based on feedback from students and employers, IRSC began to alter its EET program to support specializations in high profile technologies like Robotics and Instrumentation. In 2006 IRSC adopted the Photonics specialty, using curriculum, teaching materials and strategies developed by OP-TEC, The National Center for Optics and Photonics Education.

Indian River State College converted to the PST curriculum structure in 2008, including several other specialties such robotics, fiber optics communications, instrumentation \& control, and biomedical equipment. This change has reenergized IRSC's rapidly declining Electronics program. Enrollment is now at a maximum capacity and completers are highly sought by employers in industries such as photonics, communications, automated systems, defense and environmental control. Completers of the programs receive AAS degrees in Electronics with a specialty in Photonics, or another system specialty.

Recruitment of high school students was emphasized, using dedicated recruiters and featuring the new high profile specialties. IRSC developed robust "high school” pipelines to their new EET Systems program. Today dual credit courses are offered with six nearby high schools, which include introductory courses in the new technology areas. Student retention was improved through establishment of student cohorts, convenient course scheduling, and infusion of math tutorial videos into an electronic book version of the Fundamentals of Light and Lasers introductory text. Student enrollment in the new EET Systems program grew at a rapid rate, as shown in Figure 2. 
Figure 2 shows the declining enrollment until 2005. ${ }^{4}$ With the addition of laser and fiber optics and robotics in 2006, the trend reversed, and by 2011 IRSC has reached full capacity and maintains a waiting list for new applicants.

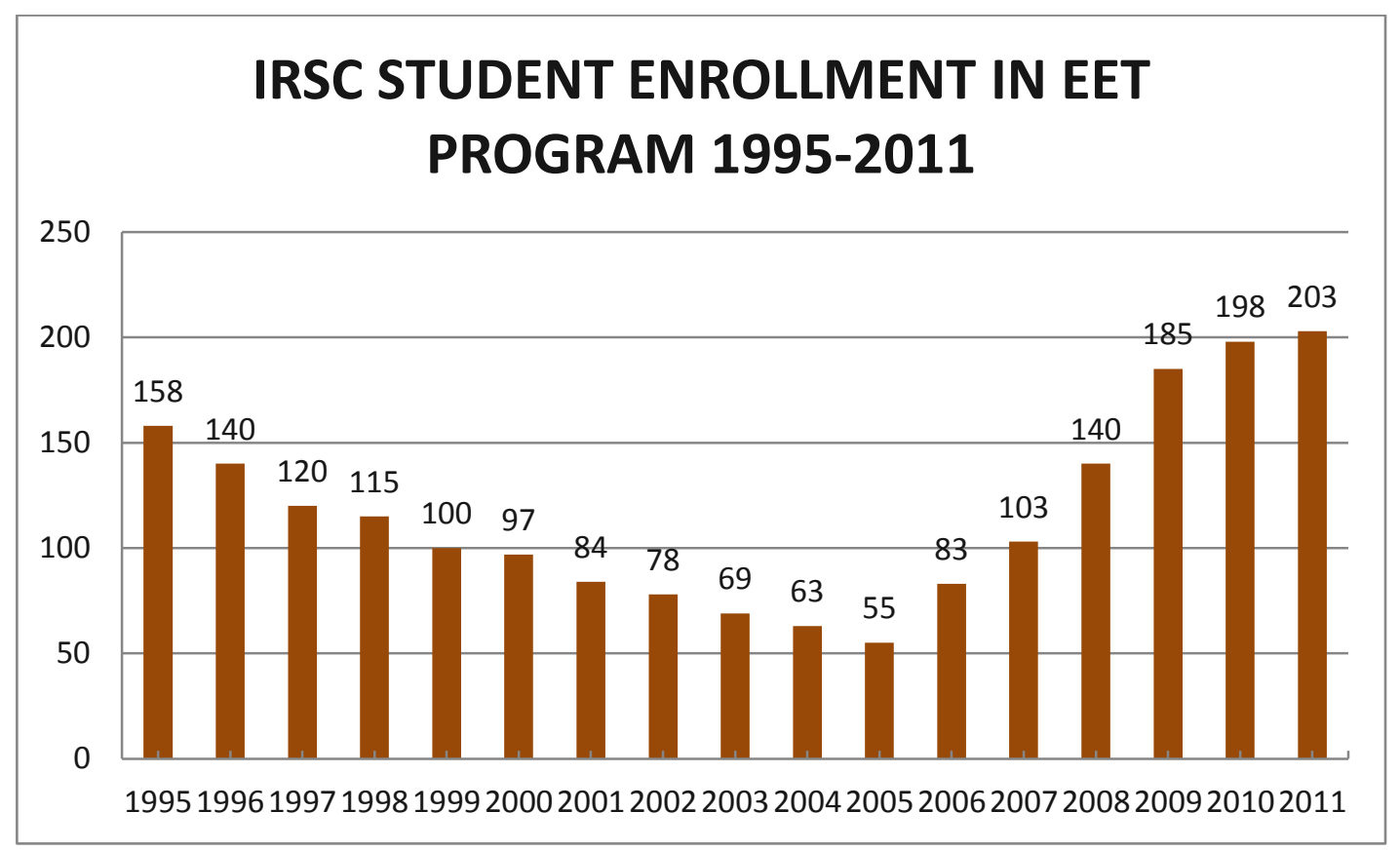

Figure 2. Effect of PST Program to IRSC Enrollment

The program shown in Table 1 has been tested and validated at Indian River State College and is the model for colleges that have electronics programs in need of curriculum updates. ${ }^{5}$

The electronics program at IRSC has always consisted of three components:

- general education,

- a required electronics core, and

- elective specialty tracks.

The "Introduction to Light and Lasers" course was added to the electronics core in 2007-8, increasing the core from 24 to 27 credit hours. To maintain the program total credit hours at 60, the elective specialty requirement was reduced from 15 to 12 credit hours. Four more courses were gradually added in the specialty course area over the period of four years (2009-2013). This gradual course addition enabled the college to distribute the cost of necessary equipment over the budgets of several years making the introduction of the PST specialty more feasible. The declining enrollment of the electronics program was not only reversed, but by 2010 IRSC reached full capacity for its current class and lab facilities. Employers are eager to hire the graduates of these specialties. In 2013, IRSC received an NSF/ATE grant to establish and operate the Southeast Regional Photonics Center, LASER-TEC. Through this Center, IRSC supports colleges that are interested in replicating its Photonics Systems Technician program. 
Table 1. IRSC Electronics Engineering Systems Technician Curriculum Options

\begin{tabular}{|c|c|}
\hline Course Groups & Credits \\
\hline $\begin{array}{ll}\text { General Education } \\
\begin{aligned} \text { 1. } & \text { English } \\
\text { 2. } & \text { Algebra } \\
\text { 3. } & \text { Trigonometry } \\
\text { 4. } & \text { Physics } \\
\text { 5. } & \text { Social Science } 1 \\
\text { 6. } & \text { Social Science } 2 \\
\text { 7. } & \text { Humanities }\end{aligned}\end{array}$ & 21 \\
\hline 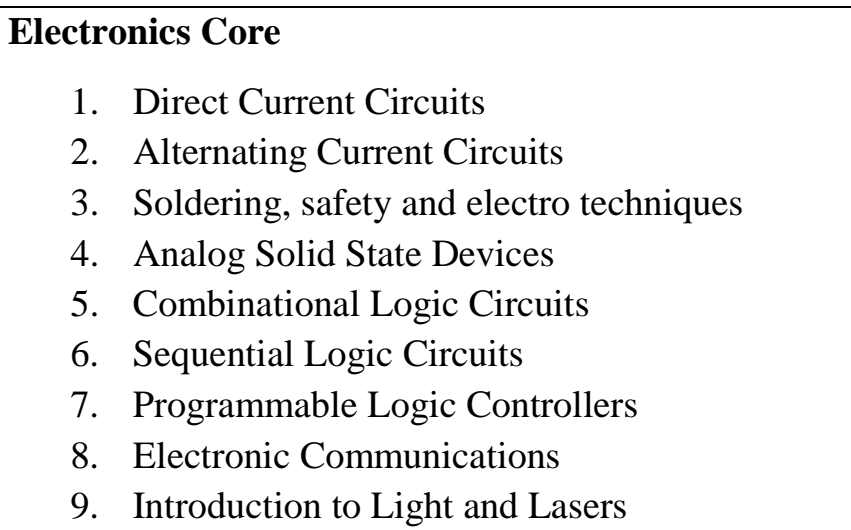 & 27 \\
\hline $\begin{array}{l}\text { Specialty Courses } \\
\text { Photonics Specialty } \\
\text { 1. Geometrical Optics } \\
\text { 2. Electro Optical Devices } \\
\text { 3. Fiber Optics } \\
\text { 4. Lasers Systems } \\
\text { Robotics Specialty } \\
\text { 5. Advanced Programmable Logic Controllers } \\
\text { 6. Intro to Robotic Systems } \\
\text { 7. Manufacturing Processes } \\
\text { 8. Capstone Project } \\
\text { Telecommunications Specialty } \\
\text { 9. Computer Repair } \\
\text { 10. Wireless Networks } \\
\text { 11. Wireless Security } \\
\text { 12. Telecommunication Systems }\end{array}$ & 12 \\
\hline TOTAL & 60 \\
\hline
\end{tabular}




\section{Replicating the Photonics Systems Technician Curriculum Model}

In 2014, 28 colleges across the U.S. have adopted the Photonics Systems Technician model. Most have begun by offering photonics courses as electives within their Electronics program. Very often, professors are reluctant to remove topics or courses from the electronics core because that is how their program was taught for years. This reluctance does not free up space in the fixed 60 credit hour curriculum for additions, and prevents the update and modernization of the program. This obstacle has been removed by surveying industry and verifying that some electronic skills are no longer needed because of technological advancements, but new ones are in demand. OP-TEC created the National Photonics Skill Standards by surveying employers from across the nation, asking which skills were the most important that PSTs must possess to be employable. ${ }^{6}$ The Skills Standards were used by OP-TEC to create three semesters of photonics courses, complete with text and lab books that are part of the PST program.

In the past a strong impediment for a college to offer photonics courses is the institutional cost for laser/optics labs and the need for specialized faculty. The PST courses do not need to be added all at once. Most colleges add one more photonics course each new fiscal year, which enables the college to distribute the cost of necessary equipment over the budget of several years. Cost for labs and equipment to teach the first photonics course is below $\$ 58,000$. Cost for each additional semester of advanced photonics is about $\$ 75,000$. The electronics faculty members are often encouraged and trained to teach these new photonics courses.

\section{Professional Development in Photonics for Photonics Faculty}

Electronics faculty with degrees in electrical engineering, do not typically have a strong enough background in optics and photonics to start a PST program. To solve this problem OP-TEC offers, at no cost, an online course in "Fundamentals of Light and Lasers" with a three day, hands on lab session offered at a college with a photonics program. This prepares the professor to teach the first photonics course. OP-TEC also conducts on-line courses to allow faculty to teach the advanced courses. Adding one course per year also allows time for electronics faculty to obtain additional professional development in lasers and electro-optics.

\section{Creating Student Interest in Pursuing Photonics Careers}

Because lasers and photonics are embedded in larger systems, they are not visible to most people. This creates the problem of lack of awareness among prospective students, especially high school students. Colleges must establish a systematic awareness campaign in local schools, lasting the entire school year, with events that promote photonic technology awareness from elementary school to the last year of high school. OP-TEC and the professional technical societies have produced materials and programs that are suitable for this type of awareness and are available to anyone. These materials include 1) DVDs describing lasers and career opportunities, 2) posters highlighting laser and optics applications, ${ }^{7}$ ) projects introducing optics and laser phenomena for students in elementary and secondary grades, ${ }^{8}$ and 4) plans, curriculum, materials and activities for high school student and teacher workshops and summer camps. ${ }^{9,10}$ 


\section{Conclusion}

Laser devices are the core technology in instruments performing vital functions in systems and applications that enable major sectors of the US economy including transportation, healthcare, and telecommunications. According to a recent National Academy of Sciences report, \$4.9 billion worth of laser sales enabled $\$ 7.5$ trillion of the U.S. gross domestic product in these three sectors in 2010. ${ }^{11}$ Laser and optical devices are also critical elements of our nation's defense and weapons systems. Photonics technicians are an important part of the technical team that is needed to assure continued economic development and defense security in the U.S. Currently our colleges are producing less than 300 new photonics technicians per year; U.S. employers need over 800 photonics techs per year. ${ }^{12}$ Rewarding careers as photonics technicians are available for deserving young people and returning veterans. Graduates of AAS degree EET programs with a Photonics Systems Specialty are receiving 4-5 job offers at annual starting salaries of \$42,000$\$ 65,000$.

In the next three years, our country needs an additional 20-30 photonics Systems Technician programs offered at two-year colleges. Creating new Photonics Systems Technician programs that are built on an electronics core allows colleges to initiate these new offerings with existing electronics faculty and labs costing less than $\$ 225,000$. And these equipment costs can be extended over three fiscal years. Curriculum, teaching materials, lab/safety designs, planning assistance, faculty development and mentoring from faculty in mature photonics programs are available without charge from OP-TEC, the NSF National Center for Optics and Photonics Education, and LASER-TEC, the NSF Regional Center for Laser and Fiber-Optics Education. ${ }^{13}$

Bibliography

1. National Center for Optics and Photonics Education, www.op-tec.org.

2. Paul Illich, Darrell M. Hull, and Paul Ruggiere, Industry Demand for Two-Year College Graduates in Optics and Photonics Technology: An Industry Survey of Current and Future Demand for Two-Year Degreed Photonics Technicians, Waco, TX: OP-TEC Monograph, 2012. Available at http://www.optec.org/2012survey.php.

3. Dan Hull, John Souders, Greg Kepner and Chrys Panayiotou, Revitalizing Electronics Engineering Technology Programs Through a Core Curriculum Structure and Emerging Technologies, Waco, TX: OP-TEC Monograph, 2008. Available at http://www.op-tec.org/pdf/Revitalizing_EET_Programs_Oct_2008.pdf.

4. Chrys Panayiotou, Transforming Electronics Engineering Technology by Infusing Photonics, Waco, TX: OPTEC Monograph, 2008). Available at http://www.op-tec.org/pdf/Revitalizing_EET_Programs_Oct_2008.pdf .

5. Ibid.

6. John Souders and Darrell Hull, The National Photonics Skill Standards for Technicians, 3rd Edition, 2008. Available at http://www.op-tec.org/skill.php.

7. SPIE, International Society for Optics and Photonics, Outreach Resources for Educators, 2014. Available at http://spie.org/x31474.xml.

8. OSA, Optical Society of America, Youth Education Resources, 2014. Available at http://www.osa.org/enus/membership_education/youth_education/.

9. John Pedrotti, TSTC Waco's Photonics Summer Institutes for High School Science and Technology Teachers, Waco, TX: OP-TEC Monograph, 2009. Available at http://www.optec.org/pdf/TSTC\%20Monograph\%20050609\%20\%28mlw\%29.pdf. 
10. Feng Zhou, Outreach Activities to Enlist High School Students for Electro-Optics Technician Programs at Indiana University of Pennsylvania, Northpointe Two-Year Campus, Waco, TX: OP-TEC Monograph, 2009. Available at http://www.op-tec.org/pdf/IUP\%20Outreach\%202009\%20Feb\%2006\%20\%28mlw\%29.pdf .

11. National Research Council. Optics and Photonics: Essential Technologies for Our Nation, the National Academies Press, 2012. Available at http://www.nap.edu/catalog.php?record_id=13491.

12. Darrell Hull and Paul Gutzwiller, Capacity Study of Photonics Colleges in the U.S, OP-TEC, 2008. Available at www.op-tec.org.

13. NSF Regional Center for Laser and Fiber-Optics Education. Available at www.laser-tec.org. 